\title{
Обобщённые банки данных (на примере ОБД «Память народа») как исторический источник о деятельности особых отделов НКВД в период Сталинградской битвы
}

\author{
Стрельников М.А. \\ Волгоградский государственный университет, \\ Россия, 400062, г. Волгоград, Университетский пр., 100 \\ E-mail: sash123450@mail.ru
}

\begin{abstract}
Аннотация. Обобщённые банки данных - это новый и актуальный ресурс для работы историков. В них содержатся материалы из различных архивов по периоду Великой Отечественной войны. В статье рассмотрены документы, включённые в один из банков данных, - «Память народа». Материалы, которые исследовались, посвящены особым отделам НКВД в период Сталинградской битвы. В статье приводится статистика количества документов, содержащихся на данном портале по указанной теме. Также рассмотрены первоначальные функции, возложенные на особые отделы НКВД, и те, которые позднее реализовывались ими в период Сталинградской битвы. Дана характеристика задач, выполняемых данными органами в рамках охранения законодательства Советского Союза (Уголовного кодекса РСФСР). Выделены задачи, которые не были возложены на особые отделы НКВД, а также дано объяснение подобного расширения функций.
\end{abstract}

Ключевые слова: Сталинградская битва, НКВД, ОБД «Память народа», особый отдел, ЦА МО.

Для цитирования: Стрельников М.А. 2021. Обобщённые банки данных (на примере ОБД «Память народа») как исторический источник о деятельность особых отделов НКВД в период Сталинградской битвы. Via in tempore. История Политология. 48 (3): 706-713. DOI 10.52575/2687-0967-2021-48-3-706-713.

\section{United open access data bank (by the way of example of united open access data bank «Memory of the People») as a historical source on the activities of the Special Departments of the NKVD during the Battle of Stalingrad}

\author{
Maksim A. Strelnikov \\ Volgograd State University, \\ 100 Universitetsky Ave., Volgograd, 400062, Russia \\ E-mail: sash123450@mail.ru
}

\begin{abstract}
United open access data banks are a new and relevant resource for the work of historians. They contain materials from various archives on the period of the Great Patriotic War. The article discusses the documents included in one of the united open access data bank - «Memory of the People». The materials that were studied are dedicated to the Special Departments of the NKVD (People's Commissariat for Internal Affairs) during the Battle of Stalingrad. The statistics of the number of documents contained on this portal on this topic was cited. It also considers the initial functions assigned to the Special Departments of the NKVD and those that were later implemented by them during the Battle of Stalingrad. The characteristics of the tasks performed by these bodies within the framework of the protection of the legislation of the Soviet Union (the Criminal Code of the Russian SFSR) are given. Tasks that were not assigned to Special Departments of the NKVD are highlighted, and an explanation is given for such an expansion of functions.
\end{abstract}


Keywords: Battle of Stalingrad, NKVD (People's Commissariat for Internal Affairs), united open access data bank «Memory of the People», Special Department, Central Archives of the Ministry of Defense of the Russian Federation.

For citation: Strelnikov M.A. 2021. United open access data bank (by the way of example of united open access data bank «Memory of the People») as a historical source on the activities of the Special Departments of the NKVD during the Battle of Stalingrad. Via in tempore. History and political science. 48 (3): 706-713 (in Russian). DOI 10.52575/2687-0967-2021-48-3-706-713.

\section{Введение}

Обобщённые банки данных (далее - ОБД) на нынешний момент являются информативными ресурсами, поскольку содержат огромный массив данных. Материалы по боевой деятельности определённых формирований можно найти на сайте ОБД «Память народа» в разделе «Документы частей». Именно данный ОБД был использован для изучения. В нынешнем исследовании рассмотрены документы особых отделов НКВД (далее - ОО НКВД), участвовавших в Сталинградской битве.

ОО НКВД возникли на основе постановления ГКО № 187сc от 17 июля 1941 г. и имели следующие задачи: «решительная борьба с шпионажем и предательством в частях Красной армии и ликвидация дезертирства» ${ }^{152}$. Однако стоит отметить, что к лету 1942 г. их функции стали расширяться, о чём свидетельствуют материалы Центрального архива Министерства обороны РФ (далее - ЦА МО). Непосредственно о деятельности ОО НКВД в период Сталинградской битвы нами было выявлено 38 документов.

\section{Объекты и методы изучения}

Объектом исследования является процесс изменения деятельности ОО НКВД в период Сталинградской битвы на основе материалов ОБД «Память народа». В исследовании были использованы как общенаучные методы (анализ и синтез, системный подход, функциональный анализ), так и частнонаучные. К последним относятся общеисторические методы, такие как нарративный, историко-генетический, историко-сравнительный, проблемный.

\section{Результаты и их обсуждение}

На данный момент имеются определённые проблемы в историографии: большинство работ имеют ознакомительный характер. Работ конкретно по деятельности НКВД в период Сталинградской битвы не так много. Новые исследования появляются часто, но в основном это статьи или тезисы докладов, а не монографии или книги. К тому же в них достаточно редко привлекаются какие-либо источники, когда же они, источники, используются, то немногочисленны.

В источниковой базе также имеются проблемы. Как уже было отмечено, вновь появляющиеся материалы (рассекречиваемые или публикуемые - М. С.) зачастую авторами игнорируются или привлекаются весьма редко. В то же время именно эти источники, например, из электронных баз данных, являются прекрасным информационным ресурсом для новых изысканий.

Кроме прочего, имеются определённые «белые пятна». Например, до сих пор нет хотя бы примерных цифр потерь соединений НКВД при обороне Сталинграда, тем более за всю битву. Традиционно указывается только цифра численности 10-й стрелковой дивизии внутренних войск НКВД (далее - ВВ НКВД) к моменту её вывода в октябре

152 Постановление ГКО о преобразовании органов 3 управления в особые отделы. URL: https://pamyat-naroda.ru/documents/view/?id=111528162 (дата обращения: 06.07.2020). 
1942 г. - 200 человек [Войска НКВД..., 2015, с. 162]. Также это касается и деятельности ОО НКВД, например, действовавших в Волжской военной флотилии.

Как уже отмечалось, в деятельности НКВД имеются и «тёмные пятна», которые созданы были в 1980-90-е гг. на волне гласности и демократизации. Вопрос эффективности применения заградительных формирований в период Великой Отечественной войны в целом и Сталинградской битвы в частности в научном сообществе не вызывают споров, в отличие от общественной среды. Вообще совмещение действий НКВД в период т. н. «большого террора» и в период войны является грубейшим нарушением принципа историзма. Даже применение общеизвестных ст. $58^{1}-58^{14}$ УК РСФСР в период военного положения нельзя сравнивать, а тем более осуждать (конечно, без должной проверки - М.С.), с мирным временем ${ }^{153}$. Это лишний раз говорит об актуальности избранной темы и необходимости её подробного изучения.

В этой связи необходимо более подробное исследование и объективное отражение деятельности ОО НКВД в период Сталинградской битвы для преодоления противоречий в обществе. Поскольку прошлое государственных органов, в т. ч. внутренних дел, имеет большое значение в формировании имиджа их современных правопреемников. На данный момент в различного рода либеральных СМИ (не только российских - М. С.) зачастую можно увидеть сравнение современных силовых структур и их предшественников ${ }^{154}$. Обычно это делается для демонизации образа современных органов правопорядка, но также от этого в обществе возникают «тёмные образы» НКВД. И разницы для обывателя между 1937 г. и 1942 г. нет, поэтому и необходимо изучение нынешней темы.

Кроме всего прочего, у названной темы имеется сугубо прикладное назначение: изучение прошлого опыта применения соединений органов внутренних дел в военное время, организация их работы в подобных условиях будут иметь положительное значение на деятельность в современных ситуациях, поскольку использование органов правопорядка в военных действиях на данном этапе имеет важное значение, например, деятельность военной полиции ${ }^{155}$ в Сирийской Арабской Республике.

Говоря об историографии, было отмечено, что в ней имеются определённые проблемы. По вопросу применения ОО НКВД в период Великой Отечественной войны в целом и Сталинградской битвы в частности исследования имеют одну особенность. Деятельность ОО НКВД рассматривается неразрывно с вопросом применения заградительных формирований [Годунов, 2015; Журило, 2015; Миненков, 2015] и приказа № 227 НКО [Новожилов, 2012; Марценюк, Ченцов, 2017].

Если обратиться к двум крупным исследователям вопроса деятельности НКВД в период Сталинградской битвы, Н.Н. Старикову и В.С. Христофорову, то ими данная проблема не была разрешена - они также рассматривают деятельность ОО НКВД

153 Вообще вопрос о репрессивной политике в СССР периода пер. пол. ХХ в. является весьма интересным и малоизученным. Во-первых, в рамках мировой практики периода - т. е. в рамках принципа историзма. Во-вторых, в рамках международной («военные тревоги» кон. 1920-х - нач. 1930-х гг., националфашистских угроз с Запада и Востока, мировой экономический кризис) и внутренней ситуаций. В-третьих, в рамках специфики советской правовой системы. В этой связи данную тему сложно назвать «закрытой», однако это стоит оставить для дальнейших изысканий.

${ }^{154}$ В лучших традициях НКВД? URL: https://echo.msk.ru/amp/blog/domozhiroff/1915452-echo/ (дата обращения: 05.05.2021). Заградотряды: первая кровь. URL: https://www.sovsekretno.ru/articles/zagradotryadypervaya-krov/ (дата обращения: 05.05.2021). Суд над Навальным прошел в лучших традициях HKBД. URL: https://amp.world.fakty.ua/366051-sud-nad-navalnym-proshel-v-luchshih-tradiciyah-nkvd (дата обращения: 05.05.2021).

${ }^{155}$ Стоит уточнить, что военная полиция включена в состав Министерства обороны РФ, однако она выполняет функции правопорядка. На наш взгляд этого достаточно для её сравнения с деятельностью формирований НКВД периода Великой Отечественной войны, поскольку некоторые войска НКВД (внутренние и пограничные) включались в состав ВС СССР, согласно Закону СССР от 1 сентября 1939 г. «О всеобщей воинской обязанности». 
неразрывно с применением заградительных формирований [Христофоров, 2008, с. 84-92; Он же, 2013, с. 402-410; Стариков, 2015, с. 103-118; Он же, 2016, с. 118-123]. Таким образом, непосредственно тема применения ОО НКВД в период Сталинградской битвы остаётся малоизученной. В этой связи стоит обратиться к ОБД «Память народа» как одной из важных источниковых баз.

Непосредственно борьба с военными преступлениями как главная функциональная задача ОО НКВД [Стариков, 2015, с. 100-101] - шпионаж, дезертирство, измена Родине $^{156}$ - представлена следующими материалами: указания № 1022 и № 1023 начальника ОО НКВД 62-й армии от 20 августа 1942 г. ${ }^{157}$, рапорт № 133 начальника ОО НКВД 95-й стрелковой дивизии от 30 декабря 1942 г. ${ }^{158}$ и выписка из показаний агента гестапо С. ${ }^{159}$ В первом документе указано, что в распоряжении ОО НКВД армии имеются сведения о нарушениях приказа НКО № 227 спустя месяц после его издания. Указания фамилий или конкретных воинских формирований нет, но говорится о «ряде командиров, комиссаров и политработников». Из этого можно сделать вывод, что подобного рода нарушения продолжались достаточно часто, причём не только простыми армейскими офицерами, но и теми, кто занимался политической работой. Стоит подчеркнуть, что это не пропагандистский приём, поскольку указание направлялось для ОО НКВД соединений 62-й армии (дивизий и танковых бригад), т. е. являлось делопроизводственной документацией.

В следующем документе рассматривается вопрос о пропаже старшего помощника оперативного отдела штаба 18-го танкового корпуса майора А.3. Пышикина - в указании лишь сообщается о случившемся подчинённым ОО НКВД соединений 62-й армии для поиска офицера и отправке его в ОО НКВД армии. Однако, исходя из приказа ГУК ВС СССР № 047 от 12 января 1948 г. ${ }^{160}$, А.З. Пышикина так и не смогли отыскать, поскольку в данном приказе он проходит как пропавший без вести.

Два последних документа относятся к деятельности ОО НКВД 95-й стрелковой дивизии по борьбе с агентами противника - был выявлен агент гестапо. Стоит отметить, что он был выявлен за несколько дней: 22 декабря был последний инструктаж, а 29 декабря уже шёл допрос. Также из контекста понятно, что агентом был бывший военнослужащий РККА. Вербовка немецкой стороной и подготовка в разведшколе гестапо заняла около двух месяцев, поскольку уже в ноябре военнослужащий был в плену.

Однако постепенно в задачу ОО НКВД стала входить борьба и с иными военными преступлениями, т. е. по ст. $193^{1}-193^{31}$ УК РСФСР. Данный процесс не был как-то санкционирован центральными органами НКВД или ГКО, однако это отражено в выявленной документации. В этой связи можно привести следующие свидетельства. Например, проверка состояния секретного делопроизводства, в т. ч. секретные переговоры

156 Данный процесс предполагает государственную проверку военнопленных, поэтому нами фильтрация не рассматривается в качестве отдельной задачи ОО НКВД [Христофоров, 2008, с. 119-120]. На сайте ОБД «Память народа» по данному вопросу также имеются материалы [Военнопленные немцы, взятые 2-4 декабря...; За последнее время имеют место факты...].

${ }^{157}$ В распоряжении особого отдела НКВД 62 А имеются данные, что ряд командиров, проявившие трусость, допускаются к выполнению служебных обязанностей. Предлагаю... URL: https://pamyatnaroda.ru/documents/view/? id=114243269 (дата обращения: 06.07.2020). По имеющимся данным ст. помощник оперативного отделения штаба 28 тк исчез с командного пункта корпуса. Немедленно примите меры к розыску. URL: https:/pamyat-naroda.ru/documents/view/?id=114243268 (дата обращения: 07.05.2021).

158 Разоблаченный особым отделом НКВД агент гестапо С. показал. URL: https://pamyatnaroda.ru/documents/view/?id=151037532 (дата обращения: 11.10.2020).

159 Выписка из показаний агента гестапо. URL: https://pamyatnaroda.ru/documents/view/?id=151037531 (дата обращения: 11.10.2020).

160 Пышикин Александр Захарович. URL: https:/pamyat-naroda.ru/heroes/memorialchelovek_prikaz75009284/ (дата обращения: 04.01.2020). 
по средствам связи ${ }^{161}$. Выявлялись нарушения по типу потери секретных документов или секретных переговоров открытым текстом.

Также кроме военных преступлений ОО НКВД стали заниматься расследованием контрреволюционных преступлений (ст. $58^{1}-58^{14}$ УК РСФСР). В качестве примера приведём вопрос отношения военнослужащих к введению погон. В докладной записке № 0073 от 16 января 1943 г. зам. начальника ОО НКВД 5-го механизированного корпуса ${ }^{162}$ сообщается, что о введении новых знаков различия политработники не проводили беседы с рядовым и средним начсоставом. В связи с этим выявлены были некоторые «нездоровые реагирования» - в основном погоны ассоциировались у бойцов либо с императорской армией, либо с немецкой. Далее в документе отмечено, что именно «антисоветских проявлений» не выявлено. Это и важно - ОО НКВД занимались также выявлением контрреволюционных преступлений.

Данный вопрос о военной цензуре был затронут В.С. Христофоровым, однако не раскрыт полностью, лишь отмечено, что ОО НКВД занимались этим совместно с органами ВЦ [Христофоров, 2008, с. 132-133].

Кроме основной правоохранительной функции ОО НКВД также занимались и иными. Например, выявление проблем в воинских формированиях 163 . В данном случае рассмотрение вопросов состояния военных объектов (переправ, оборонительных сооружений или пунктов управления) и их строительства, результативности боевой работы формирований или контроль за питанием военнослужащих находится в ведении Красной армии. Вопрос же надзора - военной прокуратуры, но не органов НКВД. Также интересно обращение к теме аморального поведения в рядах РККА ${ }^{164}$. Данным направлением занимались военно-политические органы РККА, а не ОО НКВД. Как уже отмечалось выше, возложение данных функций на ОО НКВД не прослеживается в делопроизводственной документации. Также и в иных случаях, поэтому нет необходимости вновь повторяться.

К иным функциям также можно отнести: организация разведки ${ }^{165}$, участие в приёме формирований к различным действиям (например, перед наступлением) ${ }^{166}$,

${ }^{161}$ Акт. URL: https://pamyat-naroda.ru/documents/view/?id=452457298 (дата обращения: 03.01.2021). Акт поверки состояния секретного делопроизводства штаба 20 мсбр от 17 июля 1942 года. URL: https://pamyat-naroda.ru/documents/view/?id=450448315 (дата обращения: 03.01.2021). Директивы и указания 64 A. URL: https://pamyat-naroda.ru/documents/view/?id=131308341 (дата обращения: 04.01.2021).

162 Докладная записка о реагировании личного состава 5 мк на указ ПВС о введении новых знаков различия. URL: https://pamyat-naroda.ru/documents/view/?id=135552330 (дата обращения: 04.01.2021).

$163 \mathrm{O}$ состоянии переправы в районе действия 62 A. URL: https://pamyatnaroda.ru/documents/view/?id=455161026 (дата обращения: 02.01.2021). 19. По имеющимся у меня данным, частями нашей штурмовой авиации были нанесены удары по населённому пункту. Прошу выслать справку. URL: https://pamyat-naroda.ru/documents/view/?id=454256471 (дата обращения: 04.01.2021). Специальное сообщение «О недочётах в боевой работе авиационных частей 8 BA». URL: https://pamyatnaroda.ru/documents/view/?id=454256482 (дата обращения: 04.01.2021). Специальное сообщение «О недочётах в расположении правления штаба 52 осб». URL: https://pamyatnaroda.ru/documents/view/?id=135264765 (дата обращения: 04.01.2021). Специальное сообщение об охране стыка между 78 и 116 УР и неудовлетворительном ходе строительства огневых сооружений. URL: https://pamyat-naroda.ru/documents/view/?id=135264766 (дата обращения: 04.01.2021). Спецсообщение о недостатках в питании комсостава штаба армии. URL: https://pamyatnaroda.ru/documents/view/?id=132344506 (дата обращения: 04.01.2021).

1649.2 .43 в 12.00 созовите при корпусе совещание начальников ОО НКВД. URL: https://pamyatnaroda.ru/documents/view/?id=110621074 (дата обращения: 06.07.2020). Препровождаю выписку их докладной записки опер. уполномоченного ОО НКВД при 651 отб, одновременно сообщаю. URL: https://pamyat-naroda.ru/documents/view/?id=454860716 (дата обращения: 06.07.2020).

165 Сообщаю данные о войсках противника в Сталинграде и прилегающих районах. URL: https://pamyat-naroda.ru/documents/view/?id=454256524 (дата обращения: 02.01.2021).

166 Акт. URL: https://pamyat-naroda.ru/documents/view/?id=132353295 (дата обращения: 03.01.2021). 
организация призыва военнообязанных ${ }^{167}$, участие в работе комиссий по учёту имущества, уничтоженного в результате военных действий ${ }^{168}$. Как видно - всё это не относилось к непосредственным задачам ОО НКВД. Например, сбор разведывательной информации находился в ведении разведывательных отделов армии, а призыв военнообязанных - РВК НКО.

Однако в ОО НКВД следили за проблемами не только в рядах РККА, но и в собственных. Имели место случаи неудовлетворительной работы. К таковым можно отнести развал агентурной сети ${ }^{169}$.

В то же время отношение к ОО НКВД в армейской среде было различным, в т. ч. и негативным. Имели место случаи на завершающем этапе Сталинградской битвы игнорирования со стороны старшего офицерского состава (командиры дивизий и начальники штабов - М. С.) органов НКВД ${ }^{170}$. Объяснить это можно тем, что работа, которая выполнялась ОО НКВД, выходила за рамки их непосредственных задач. В этой связи вполне объективно будет иметь место пренебрежительное, а иногда и враждебное отношение к «особистам» со стороны командиров РККА.

Остальные материалы - это делопроизводственная документация, которая не имеет важного значения для исследования деятельности НКВД в период Сталинградской битвы ${ }^{171}$. Единственное, что может быть полезным - это сообщение врид начальника ОО НКВД Донского фронта В.М. Казакевича о передислокации данного формирования ${ }^{172}$, поскольку в данном документе содержатся сведения о численности личного состава отряда.

${ }^{167}$ Командующий армии приказал представить ОО НКВД армии именной список. URL: https://pamyat-naroda.ru/documents/view/?id=110621261 (дата обращения: 06.07.2020).

168 Акт. URL: https://pamyat-naroda.ru/documents/view/?id=114393522 (дата обращения: 03.01.2021). Акт. URL: https://pamyat-naroda.ru/documents/view/?id=455018059 (дата обращения: 03.01.2021). Специальное сообщение. URL: https://pamyat-naroda.ru/documents/view/?id=454256532 (дата обращения: 02.01.2021).

169 Приказ начальника особого отдела НКВД 62 A. URL: https:/pamyatnaroda.ru/documents/view/?id=114243237 (дата обращения: 06.07.2020).

${ }^{170}$ Имею сведения, что отдельные командиры дивизий проявляют нездоровые отношения к аппарату особого отдела НКВД. URL: https://pamyat-naroda.ru/documents/view/?id=50108067 (дата обращения: 06.07.2020).

${ }^{171}$ Боевое донесение. URL: https://pamyat-naroda.ru/documents/view/?id=132351702 (дата обращения: 03.01.2021). Отмечается, что многие начальники и оперуполномоченные ослабили работу с резидентами и агентурой, предлагаю руководствоваться следующим. URL: https:/pamyatnaroda.ru/documents/view/?id=114243229 (дата обращения: 04.01.2021). Постановлением ГКО № 406 уполномоченные $\mathrm{OO}$ в полках и отдельных частях подчинены командирам полков с одновременным подчинением их органам НКВД. URL: https://pamyat-naroda.ru/documents/view/?id=454984038 (дата обращения: 02.01.2021). Приказом НКВД ССCP № 001287 установлена ежесуточная отчетность. URL: https://pamyat-naroda.ru/documents/view/?id=114243238 (дата обращения: 07.07.2020). Прошу для ОО НКВД 8 BA высылать копии всех приказов, издаваемых по 8 BA. URL: https://pamyatnaroda.ru/documents/view/?id=454256499 (дата обращения: 06.07.2020). С получением сего предлагаю: все документы $\mathrm{OO}$ фронта возвратить в naroda.ru/documents/view/?id=113436350 (дата обращения: 03.01.2021). Сведения начальника ОО ДонФ. URL: https://pamyat-naroda.ru/documents/view/? id=133339984 (дата обращения: 03.01.2021). Сводный эскадрон 20 гв. кп 5 гв. кд, в бою под с. Алексеевка танками противника был отсечён от полка. URL: https://pamyat-naroda.ru/documents/view/?id=153710772 (дата обращения: 04.01.2021). Сегодня прошу выслать ко мне вновь назначенного начальника финчасти. URL: https://pamyatnaroda.ru/documents/view/? id=455436157 (дата обращения: 03.01.2021). Сообщаем, что со стороны особого отдела НКВД ЮЗФ препятствий не встречается в использовании на работе в ЮЗН чертёжниками. URL: https://pamyat-naroda.ru/documents/view/?id=114790408 (дата обращения: 06.07.2020).

${ }_{172}$ Сообщаю, что для передислоцирования особого отдела НКВД ДонФ необходимо. URL: https://pamyat-naroda.ru/documents/view/?id=133340008 (дата обращения: 06.07.2020). 


\section{Заключение}

Из всего этого следует, что ОО НКВД уже ко второму периоду Великой Отечественной войны стали выполнять множество задач, которые не были на них возложены. Можно сказать, что таким образом прежняя работа органов НКВД была перестроена с учётом военного времени, как, например, прокуратуры. Как и ранее органы правопорядка выполняли различные задачи, в т. ч. и те, которые на них не возлагались. Например, надзор находился в ведении прокуратуры, а не НКВД.

Таким образом, можно утверждать, что ОО НКВД заменили собой территориальные органы НКВД в районах действия военного положения с теми же широкими полномочиями: занимались не просто фильтрацией и выявлением шпионов и диверсантов, а расследованием военных и государственных (контрреволюционных) преступлений без исключения, а также надзором и т. д. Вообще впервые была рассмотрена документация ОО НКВД и их деятельность отдельно от вопроса применения заградительных формирований.

Если обратиться к обобщённым банкам данных, то нельзя не отметить, что тема деятельности ОО НКВД был впервые рассмотрена на основе материалов электронной базы данных. Вообще, как уже отмечалось, материалы ОБД массово не привлекаются, поэтому новизна исследования состоит ещё и в этом.

В этой связи стоит более активно привлекать данные из баз для исследований, особенно относительно деятельности НКВД в период Сталинградской битвы. Однако нельзя не отметить, что использование лишь одних ОБД не может полностью охарактеризовать какое-либо явление или процесс, как, например, нынешний. Необходимо кроме данных ресурсов использовать материалы архивов (в ОБД содержатся материалы лишь одного или двух архивов, причём не все - М. С.), в т. ч. ведомственных.

\section{Список литературы}

1. Войска НКВД в Великой Отечественной войне : Военно-исторический труд : В 3 т. T. II. Войска НКВД в первый и второй периоды Великой Отечественной войны (1941-1943) / под общ. ред. В.В. Золотова. М., На боевом посту, 2015, 328.

2. Годунов А.С. 2015. Заградотряды Красной армии и войск НКВД в Великой Отечественной войне (историко-правовой аспект служебно-боевого применения). В сб.: 70 лет Победы: история и современность : Материалы межвуз. студен. форума. М.: Международный юридический институт, 2015: 55-61.

3. Журило П.И. 2015. Заградительные отряды: мифы и факты. В сб.: Великая Отечественная война: нравственные аспекты и историческое наследие : материалы Всерос. науч.теорет. конф. молодых исследователей : В 2-х ч. Ч. 1 (г. Санкт-Петербург, 29 апреля 2015 г.). СПб.: СПбУ МВД РФ: $119-122$.

4. Марценюк Ю.А., Ченцов А.С. 2017. Приказ народного комиссара обороны от 28 июля 1942 года № 227. Правда и вымысел. Академический вестник войск национальной гвардии РФ, 2 (35): $23-28$.

5. Миненков Д.Д. 2015. Заградительные отряды НКВД и НКО во время Великой Отечественной войны. Опровержение фальсификаций советской военной истории. Академический вестник ВВ МВД России, 3 (28): 42-46.

6. Новожилов В.Ю. 2012. Приказ № 227-1942 г. «Ни шагу назад»: правда и вымысел. Академический вестник ВВ МВД России, 4 (17): 17-22.

7. Стариков Н.Н. 2015. Войска НКВД в Сталинградской битве. М., Алисторус, 2015, 400.

8. Стариков Н.Н. 2016. Войска НКВД на фронте и в тылу. М., Эксмо, 2016, 320.

9. Христофоров В.С. 2008. Сталинград. Органы НКВД накануне и в дни сражения. М., Московские учебники и Картолитография, 2008, 240.

10. Христофоров В.С. 2013. История страны в документах архивов ФСБ : Сб. ст. и материалов. М., Главархив Москвы, 2013, 960. 


\section{References}

1. Voyska NKVD v Velikoy Otechestvennoy voyne : Voenno-istoricheskiy trud : V 3 t. T. II. Voyska NKVD v pervyy i vtoroy periody Velikoy Otechestvennoy voyny (1941-1943) [Troops of the NKVD in the Great Patriotic War: Military-historical work: In 3 volumes. Vol. II. NKVD troops in the first and second periods of the Great Patriotic War (1941-1943)] / pod obshch. red. V.V. Zolotova. Moscow, Na boevom postu, 2015, 328 .

2. Godunov A.S. 2015. Zagradotryady Krasnoy armii i voysk NKVD v Velikoy Otechestvennoy voyne (istoriko-pravovoy aspekt sluzhebno-boevogo primeneniya) [Barrage detachments of the Red Army and NKVD troops in the Great Patriotic War (historical and legal aspect of service and combat use)]. In: 70 let Pobedy: istoriya i sovremennost' : Materialy mezhvuz. studen. foruma. Moscow, Mezhdunarodnyy yuridicheskiy institut, 2015: 55-61 (in Russian).

3. Zhurilo P.I. 2015. Zagraditel'nye otryady: mify i fakty [Defensive detachments: myths and facts]. In: Velikaya Otechestvennaya voyna: nravstvennye aspekty i istoricheskoe nasledie : materialy Vseros. nauch.-teoret. konf. molodykh issledovateley : V 2 ch. Ch. 1 (Saint-Petersburg, 29 April, 2015). Saint-Petersburg, St. Petersburg University of the Russian Interior Ministry: 119-122 (in Russian).

4. Martsenyuk Yu. A., Chentsov A.S. 2017. Prikaz narodnogo komissara oborony ot 28 iyulya 1942 goda No. 227. Pravda i vymysel [Order of the People's Commissar of Defense of July 28, 1942 No. 227. Truth and Fiction]. Akademicheskiy vestnik voysk natsional'noy gvardii RF, 2 (35): 23-28 (in Russian).

5. Minenkov D.D. 2015. Zagraditel'nye otryady NKVD i NKO vo vremya Velikoy Otechestvennoy voyny. Oproverzhenie fal'sifikatsiy sovetskoy voennoy istorii [Defensive detachments of the NKVD and NKO during the Great Patriotic War. Refutation of falsifications of Soviet military history]. Akademicheskiy vestnik VV MVD Rossii, 3 (28): 42-46 (in Russian).

6. Novozhilov V. Yu. 2012. Prikaz No. 227-1942 g. «Ni shagu nazad»: pravda i vymysel [Order No. 227-1942 «Not a step back»: truth and fiction]. Akademicheskiy vestnik VV MVD Rossii, 4 (17): 17-22 (in Russian).

7. Starikov N.N. 2015. Voyska NKVD v Stalingradskoy bitve [Troops of the NKVD in the Battle of Stalingrad]. Moscow, Alistorus, 2015, 400 (in Russian).

8. Starikov N.N. 2016. Voyska NKVD na fronte i v tylu [Troops of the NKVD at the front and in the rear]. Moscow, Eksmo, 2016, 320 (in Russian).

9. Khristoforov V.S. 2008. Stalingrad. Organy NKVD nakanune i v dni srazheniya [Stalingrad. Bodies of the NKVD on the eve and in the days of the battle]. Moscow, Moskovskie uchebniki $\mathrm{i}$ Kartolitografiya, 2008, 240 (in Russian).

10. Khristoforov V.S. 2013. Istoriya strany v dokumentakh arkhivov FSB: Sb. st. i materialov [History of the country in the documents of the FSB archives: Sat. Art. and materials]. Moscow, Glavarkhiv Moskvy, 2013, 960 (in Russian).

Конфликт интересов: о потенциальном конфликте интересов не сообщалось.

Conflict of interest: no potential conflict of interest related to this article was reported.

\section{ИНФОРМАЦИЯ ОБ АВТОРЕ}

Стрельников Максим Александрович, магистрант 2 курса кафедры отечественной и всеобщей истории, археологии Волгоградского государственного университета, г. Волгоград, Россия

\section{INFORMATION ABOUT THE AUTHOR}

Maksim A. Strelnikov, undergraduate student 2nd year Department of Russian and World History, Archeology of Volgograd State University, Volgograd, Russia 